\title{
ORIGINAL ARTICLE Role of mineralocorticoid receptor/Rho/Rho-kinase pathway in obesity-related renal injury
}

\author{
H Tokuyama, S Wakino, Y Hara, N Washida, K Fujimura, K Hosoya, K Yoshioka, K Hasegawa, H Minakuchi, K Homma, K Hayashi \\ and $\mathrm{H}$ Itoh
}

\begin{abstract}
OBJECTIVE: We examined whether aldosterone/Rho/Rho-kinase pathway contributed to obesity-associated nephropathy. SUBJECTS: C57BL/6J mice were fed a high fat or low fat diet, and mice on a high fat diet were treated with a mineralocorticoid receptor antagonist, eplerenone.

RESULTS: The mice on a high fat diet not only developed obesity, but also manifested renal histological changes, including glomerular hypercellularity and increased mesangial matrix, which paralleled the increase in albuminuria. Furthermore, enhanced Rho-kinase activity was noted in kidneys from high fat diet-fed mice, as well as increased expressions of inflammatory chemokines. All of these changes were attenuated by eplerenone. In high fat diet-fed mice, mineralocorticoid receptor protein levels in the nuclear fraction and SGK1, an effector of aldosterone, were upregulated in kidneys, although serum aldosterone levels were unaltered. Furthermore, aldosterone and $3 \beta$-hydroxysteroid dehydrogenase in renal tissues were upregulated in high fat diet-fed mice. Finally, in cultured mesangial cells, stimulation with aldosterone enhanced Rho-kinase activity, and pre-incubation with eplerenone prevented the aldosterone-induced activation of Rho kinase.

CONCLUSION: Excess fat intake causes obesity and renal injury in $\mathrm{C} 57 \mathrm{BL} / 6 \mathrm{~J}$ mice, and these changes are mediated by an enhanced mineralocorticoid receptor/Rho/Rho-kinase pathway and inflammatory process. Mineralocorticoid receptor activation in the kidney tissue and the subsequent Rho-kinase stimulation are likely to participate in the development of obesityassociated nephropathy without elevation in serum aldosterone levels.
\end{abstract}

International Journal of Obesity (2012) 36, 1062-1071; doi:10.1038/ijo.2011.232; published online 20 December 2011

Keywords: metabolic syndrome; aldosterone; SGK1; MCP1; adipose tissue

\section{INTRODUCTION}

A growing body of evidence has suggested that obesity is causally linked to various disorders, including dyslipidemia and hyperglycemia. Furthermore, obesity is recognized increasingly as a major risk factor for chronic kidney disease (CKD). ${ }^{1}$ It has been shown that renal structural and functional changes develop early in the course of obesity-initiated metabolic syndrome and apparently mimic those observed in diabetic nephropathy. ${ }^{2}$ Furthermore, obesity causes glomerular hyperfiltration and alterations in several humoral factors, including hyperinsulinemia and activated reninangiotensin system, all of which could precipitate in more severe glomerular damage associated with obesity. Nevertheless, specific factors contributing to the initiation and progression of obesityinduced renal dysfunction have not been determined thus far.

A small GTP-binding protein, Rho, and its effector, Rho kinase, have several physiological and pathological functions. ${ }^{3}$ It has been established that the activation of the Rho/Rho-kinase pathway plays an important role not only in the enhanced systemic vascular tone in several models of hypertensive animals, ${ }^{4,5}$ but also in cellular pathophysiological processes, including migration, proliferation, epithelial-mesenchymal transdifferentiation and matrix production. ${ }^{6,7}$ Moreover, in the kidney, the Rho/Rho-kinase pathway regulates basal and angiotensin II-induced tone of afferent and efferent arterioles, ${ }^{8,9}$ and is activated in hypertensive glomerulosclerosis and interstitial fibrosis. ${ }^{10,11}$ Of note, a recent study has demonstrated that activation of Rho/Rhokinase pathway interferes with insulin signaling through serine phosphorylation of insulin receptor substrate-1 in cultured vascular smooth muscle cells. ${ }^{12}$ Conversely, the blockade of the Rho/Rhokinase pathway has been shown to ameliorate insulin sensitivity and impairment of endothelial dysfunction in Zucker obese rats. ${ }^{13}$ It can be surmised therefore that the Rho/Rho-kinase pathway constitutes a critical mediator linking between metabolic and hemodynamic abnormalities in insulin resistance and obesity.

Several lines of recent studies have documented a potential role of aldosterone in the pathogenesis of renal injury. Severe glomerular injury and interstitial fibrosis were observed in rats treated with aldosterone and salt. ${ }^{14,15}$ In patients with CKD and early diabetic nephropathy, the addition of mineralocorticoid receptor (MR) antagonists to angiotensin-converting enzyme inhibitors had no hemodynamic effects, but markedly reduced proteinuria. ${ }^{16,17}$ Further studies also reported that monotherapy with MR antagonists was more effective than angiotensinconverting enzyme inhibitors in reducing proteinuria in hypertensive patients. ${ }^{18,19}$ Furthermore, aldosterone-induced Rho-kinase activation elicits myofibroblastic transformation in renal cells and contributes to the progression of renal fibrosis. ${ }^{20,21}$ Little is known, however, as to the role of Rho kinase as an effector of aldosterone in obesity-associated renal injury.

In this study, we investigated whether the aldosterone/Rho/ Rho-kinase pathway was activated and contributed to the development of renal injury in obese animals. Furthermore, the mechanisms for the enhanced aldosterone/Rho/Rho-kinase pathway in mediating the obesity-associated nephropathy were assessed. 


\section{SUBJECTS AND METHODS}

\section{Animals-1}

The 6-week-old male C57BL/6J mice weighing $20 \pm 1 \mathrm{~g}$ were housed in a temperature- and light-controlled room $\left(22 \pm 1{ }^{\circ} \mathrm{C}\right.$; 12-h light day cycle) with ad libitum access to tap water and a standard mouse chow. Animals were fed a low fat diet (LFD, $n=8 ; 10 \%$ lard; Research Diets Inc., New Brunswick, NJ, USA) or a high fat diet (HFD, $n=8 ; 60 \%$ lard; Research Diets Inc.), with the latter further randomized to either an MR inhibitor (eplerenone, $100 \mathrm{mg} \mathrm{kg}^{-1}$ per day, via gavage, $n=8$; Pfizer Inc., Tokyo, Japan)-treated or a vehicle-treated group $(n=8)$ during the 12-week experimental protocol. Animals received daily gavage with either eplerenone or vehicle control until being killed on week 12. Daily food intake was measured in each group.

We implanted a telemetry transmitter probe (model PA-C20; Data Sciences Int., St Paul, MN, USA) into the 6-week-old male mice under sodium pentobarbital anesthesia ( $50 \mathrm{mg} \mathrm{kg}^{-1}$ intraperitoneally), and the flexible tip of the probe was positioned at the cervical arteries as described previously. ${ }^{22}$ The mice were returned to their home cages and allowed to recover for 2 weeks before the start of the measurements. We monitored conscious blood pressure (BP), heart rate and the activity in unrestricted and untethered mice with the Dataquest IV system (Data Sciences Int.). ${ }^{22}$

After 12-week treatment with eplerenone, body weight was recorded. Mice were then anesthetized with ether and the abdomen was opened through a mid-line incision. Blood and urine were drawn for measuring biochemical assays. Kidneys were harvested and sliced sagitally. The half was snap frozen in liquid nitrogen and stored at $-80^{\circ} \mathrm{C}$ and the remaining was immersed in $10 \%$ neutral-buffered formalin and embedded in paraffin. The study protocol was performed in accordance with the animal experimentation guideline of Keio University School of Medicine.

\section{Animals-2}

To evaluate the renoprotective effects of the Rho-kinase inhibition, animals were fed an LFD ( $n=8 ; 10 \%$ lard; Research Diets Inc.) or an HFD $(n=8 ; 60 \%$ lard; Research Diets Inc.) in the same way, with the latter further randomized to either a Rho-kinase inhibitor (fasudil, $30 \mathrm{mg} \mathrm{kg}^{-1}$ per day, via gavage, $n=8$; Asahi Kasei Co., Tokyo, Japan)-treated or a vehicletreated group $(n=8)$ during the experimental protocol. After 12-week treatment with fasudil, the mice were killed and the collection of blood, urine and tissues were performed in the same way as in Animal-1.

\section{Morphological examination}

Nuclei within a single glomerulus were counted in 50 hilar glomeruli in each animal. Diameters of glomeruli were measured by photographing at high magnification for image analysis. ${ }^{23}$ These morphological evaluations were conducted by two independent observers in a blinded manner.

\section{Immunohistochemistry}

Kidney sections $(4 \mu \mathrm{m})$ were stained with periodic acid-Schiff's, monoclonal mouse macrophage marker F4/80 (1:300 dilution) and Masson's modified trichrome to demonstrate collagen matrix. ${ }^{23,24}$ The accumulation of matrix, and the extent of histochemical and immunohistochemical staining were quantified using computer-assisted image analysis. The number of macrophages was assessed by counting F4/80-positive nuclei (brown) per $\mathrm{mm}^{2}$ with the use of image analysis software. ${ }^{23}$ Sections incubated with normal goat serum instead of the primary antiserum served as the negative control.

\section{Tissue aldosterone and immunoblotting}

Tissue aldosterone was measured by liquid chromatography-electrospray ionization tandem mass spectrometry. ${ }^{25}$ Western blotting was performed as described previously. ${ }^{13}$ To examine the effects of aldosterone on Rho/Rho-kinase pathway, phosphorylated levels of myosin phosphatase target subunit-1 (MYPT1; Upstate Biochemistry, Lake Placid, NY, USA), one of the substrates of Rho kinase, were examined in the kidney and aldosterone-stimulated human mesangial cells (HMCs), with the use of phospho-MYPT1 levels at the inhibitory site (Thr696) as a marker for Rho-kinase activity. Immunoblotting was performed using specific antibodies against phospho-MYPT1 and mitogen-activated protein kinases, including extracellular signal-regulated kinases (ERK1/2) and p38. ${ }^{26,27}$

We prepared the nuclear extracts with commercially available kits (Panomics Inc., Fremont, CA, USA). ${ }^{28}$ MR (Perseus Proteomics, Tokyo, Japan) protein levels in the nuclear fraction of the kidney were examined. Immunoreactive bands were detected using an ECL detection kit (Amersham Biosciences, Uppsala, Sweden).

\section{Measurement of MCP-1 and TNF- $\alpha$ protein levels}

Tissue monocyte chemoattractant protein-1 (MCP-1) and tumor necrosis factor- $\alpha$ (TNF- $\alpha$ ) were measured using a commercially available enzymelinked immunosorbent assay kit (Westang Bio-tech, Shanghai, China). ${ }^{29}$ Briefly, kidney samples were homogenized separately in $0.1 \mathrm{M} \mathrm{NaCl}, 0.05 \mathrm{M}$ Tris-Cl and $2 \%\left(\mathrm{v} \mathrm{v}^{-1}\right)$ Triton X-100 together with protease inhibitors (Roche Diagnostics, Melbourne, Australia). After centrifugation, the supernatants were collected and stored at $-80{ }^{\circ} \mathrm{C}$ until assayed. The TNF- $\alpha$ and MCP-1 levels were measured using an enzyme-linked immunosorbent assay kit. All samples were assayed in duplicate. The results of TNF- $\alpha$ and MCP-1 were calculated as concentration per wet weight of the tissue (picograms per gram).

\section{Cell culture and experimental protocols}

Experiment-1. Aldosterone was obtained from Sigma (St Louis, MO, USA). An aldosterone receptor blocker, eplerenone, was kindly provided by Pfizer Inc.. HMCs in primary culture were purchased from Cambrex Bioproducts (Takara Bio Inc., Otsu, Shiga, Japan). The cells were cultured in SmBM medium (Clonetics Co., Walkersville, MD, USA) supplemented with $10 \%$ fetal bovine serum. For all experiments, early passaged (passages 3-6) HMCs were grown at $60-70 \%$ confluence and made quiescent by serum starvation for $48 \mathrm{~h}$. Cells were incubated with various concentration of aldosterone $\left(10^{-11}\right.$ to $\left.10^{-8} \mathrm{moll}^{-1}\right)$ for $1 \mathrm{~h}$ and were also treated with eplerenone for $30 \mathrm{~min}$ before the addition of aldosterone $\left(1 \mathrm{nmoll}^{-1}\right)$. HMCs were harvested in $100 \mu$ lysis buffer containing $20 \mathrm{mmoll}^{-1}$ of Tris$\mathrm{HCl}, 250 \mathrm{mmol}^{-1}$ of sucrose and phenylmethylsulfonyl fluoride, as well as aprotinin and leupeptin $\left(10 \mu \mathrm{g} \mathrm{ml}^{-1}\right.$ each) $5 \mathrm{~min}$ after the aldosterone treatment. After three cycles of freeze and thaw, samples were centrifuged at $250 \mathrm{~g}$ at $4{ }^{\circ} \mathrm{C}$ for $5 \mathrm{~min}$. The supernatant was then centrifuged at $100000 \mathrm{~g}$ for $30 \mathrm{~min}$ at $4^{\circ} \mathrm{C}$. The supernatant was saved and the protein was subjected to immunoblotting.

Experiment-2. Cells were further supplemented with $100 \mathrm{~nm}$ human insulin (Sigma) in $2 \%$ fetal bovine serum, to mimic hyperinsulinemia, or incubated with standard $1 \mathrm{~nm}$ or $10 \mathrm{~nm}$ insulin in Dulbecco's modified Eagle's medium with $20 \%$ fetal bovine serum over 48 -h period. Cells were cultured in $75-\mathrm{cm}^{2}$ flasks (90-95\% confluency) for RNA isolation.

\section{Quantitative real-time reverse transcription-polymerase chain} reaction

Total RNA was extracted from the mouse kidneys using Trizol solution (Invitrogen, Carlsbad, CA, USA). Total RNA was subjected to reverse transcription in a $20 \mu \mathrm{l}$ reaction mixture containing random primers and Superscript II enzyme (Invitrogen). Quantitative real-time polymerase chain reaction was performed with an $\mathrm{ABI}$ Prism 7700 Sequence Detection System using SYBR Green PCR Master Mix Reagent Kit (Applied Biosystems, Foster City, CA, USA). ${ }^{30}$ Primers used were as follows: serum- and glucocorticoid-induced kinase 1 (SGK1): sense-5'-TGTCTTGGGGCTGTCC TGTATG-3', antisense-5'-GCTTCTGCTGCTTCCTTCACAC-3'; platelet-derived growth factor subunit B (PDGF-B): sense- $5^{\prime}$-CGAGTGCAAGACGCGTACA-3', antisense- $5^{\prime}$-GGCATTGGTGCGATCGA- $3^{\prime}$; TNF- $\alpha$ : sense- $5^{\prime}$-GGTGATCGGTCC CAACAAGGA-3', antisense-5'-CACGCTGGCTCAGCCACTC-3'; MCP-1: sense5'-TAGGCTGGAGAGCTACAAGAGGAT-3', antisense-5'-AGACCTCTCTCTTGAG CTTGGTGA-3'; CYP11B1: sense-5'-ACTCCGTGGCCTGAGACG-3', antisense5'-CTCTGCCAGTTCGCGATA-3'; CYP11B2: sense-5'-ACTCCGTGGCCTGAGA

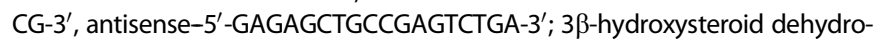
genase (33-HSD): sense- $5^{\prime}$-GCAGACCATCCTAGATGTCAATCTG- $3^{\prime}$, antisense5'-CAAGTGGCTCATAGCCCAGATCTC-3'; and CYP21 hydroxylase: sense- $5^{\prime}$-CA 
1064

AGAAACTCTCTCGCTCAGCCCT-3', antisense-5'-CAACGTGCTGTCCTTGTCTCCA $A A-3^{\prime}$. Polymerase chain reaction-amplified products were also electrophoresed on agarose gels to confirm that single bands were amplified. Levels of mRNA were normalized to those of $\beta$-actin (primers commercially available from Applied Biosystems).

\section{Statistics}

Results are expressed as mean \pm s.e.m. Statistical significance was evaluated with the analysis of variance with a least significant difference post-hoc comparison using the SPSS software package (SPSS Inc., Chicago, IL, USA). Histological results were analyzed by Kruskal-Wallis nonparametric test. $P$-values $<0.05$ were considered statistically significant.

\section{RESULTS}

Effects of eplerenone on systemic blood pressure, renal function and metabolic parameters

Systolic BP, mean BP and heart rate were unaltered by an HFD. Systolic and mean BP tended to be reduced by eplerenone, but did not attain statistical significance $(P>0.1$; Figure $1 \mathrm{a}-\mathrm{c})$ Albuminuria was markedly increased in mice on HFD compared with those on an LFD $(P<0.01$; Figure 1d). The treatment with eplerenone reduced albuminuria nearly to the level of mice on LFD. Serum creatinine was not changed in mice on HFD nor was altered by eplerenone (LFD, $0.13 \pm 0.02 \mathrm{mg} \mathrm{dl}^{-1}$; HFD $0.18 \pm 0.06 \mathrm{mg} \mathrm{dl}^{-1}$; HFD with eplerenone, $0.14 \pm 0.02 \mathrm{mg} \mathrm{dl}^{-1}$; $P>0.1$ ). Body weights and kidney weights of mice on HFD were markedly greater than those of mice on LFD $(P<0.05$; Figure $1 \mathrm{e}$ and f). HFD-induced obesity was ameliorated by the treatment with eplerenone. Eplerenone did not affect the amount of food intake (LFD, $1.9 \pm 0.1 \mathrm{~g}$ per day; HFD, $1.9 \pm 0.1 \mathrm{~g}$ per day; HFD with eplerenone, $2.0 \pm 0.1 \mathrm{~g}$ per day).

HFD had no significant effect on blood glucose levels (LFD, $175 \pm 5 \mathrm{mg} \mathrm{dl}^{-1}$; HFD, $196 \pm 41 \mathrm{mg} \mathrm{dl}^{-1}$; HFD with eplerenone, $206 \pm 14 \mathrm{mg} \mathrm{dl}^{-1}$ ) or triglycerides (LFD, $69 \pm 10 \mathrm{mg} \mathrm{dl}^{-1}$; HFD, $95 \pm 32 \mathrm{mg} \mathrm{dl}^{-1}$; HFD with eplerenone, $76 \pm 17 \mathrm{mg} \mathrm{dl}^{-1}$ ), but caused increases in serum insulin (LFD, $0.72 \pm 0.175 \mathrm{ng} \mathrm{ml}^{-1}$; HFD, $7.56 \pm 2.35 \mathrm{ng} \mathrm{ml}^{-1} ; P<0.05$ vs LFD), as well as free fatty acid (FFA) (LFD, $0.65 \pm 0.09 \mathrm{mg} \mathrm{dl}^{-1}$; HFD, $1.25 \pm 0.16 \mathrm{mg} \mathrm{dl}^{-1}$; $P<0.05$ vs LFD) and total cholesterol (LFD, $107 \pm 6 \mathrm{mg} \mathrm{dl}^{-1}$; HFD, $191 \pm 34 \mathrm{mg} \mathrm{dl}^{-1} ; P<0.05$ vs LFD). Elevated levels of insulin and FFA were ameliorated by the treatment with eplerenone (insulin: HFD + eplerenone, $2.04 \pm 0.34 \mathrm{ng} \mathrm{ml}^{-1}, P<0.05$ vs HFD; FFA: HFD + eplerenone, $0.71 \pm 0.1 \mathrm{ng} \mathrm{ml}^{-1}, P<0.05$ vs HFD).

Effects of eplerenone on renal morphological changes and renal expression of inflammatory chemokines

In kidneys from mice on HFD, marked mesangial hypercellularity and enlarged glomerular size were noted (Figure 2a). As shown in Figure 2c, glomerular size was increased in mice on HFD compared with that in mice on LFD $(P<0.01)$. Similarly, when assessed by the number of the nucleus, glomerular cellularity was increased in mice on HFD compared with that in mice on LFD $(66.7 \pm 3.0$ vs $32.3 \pm 2.5$ nuclei per glomerular cross-section,
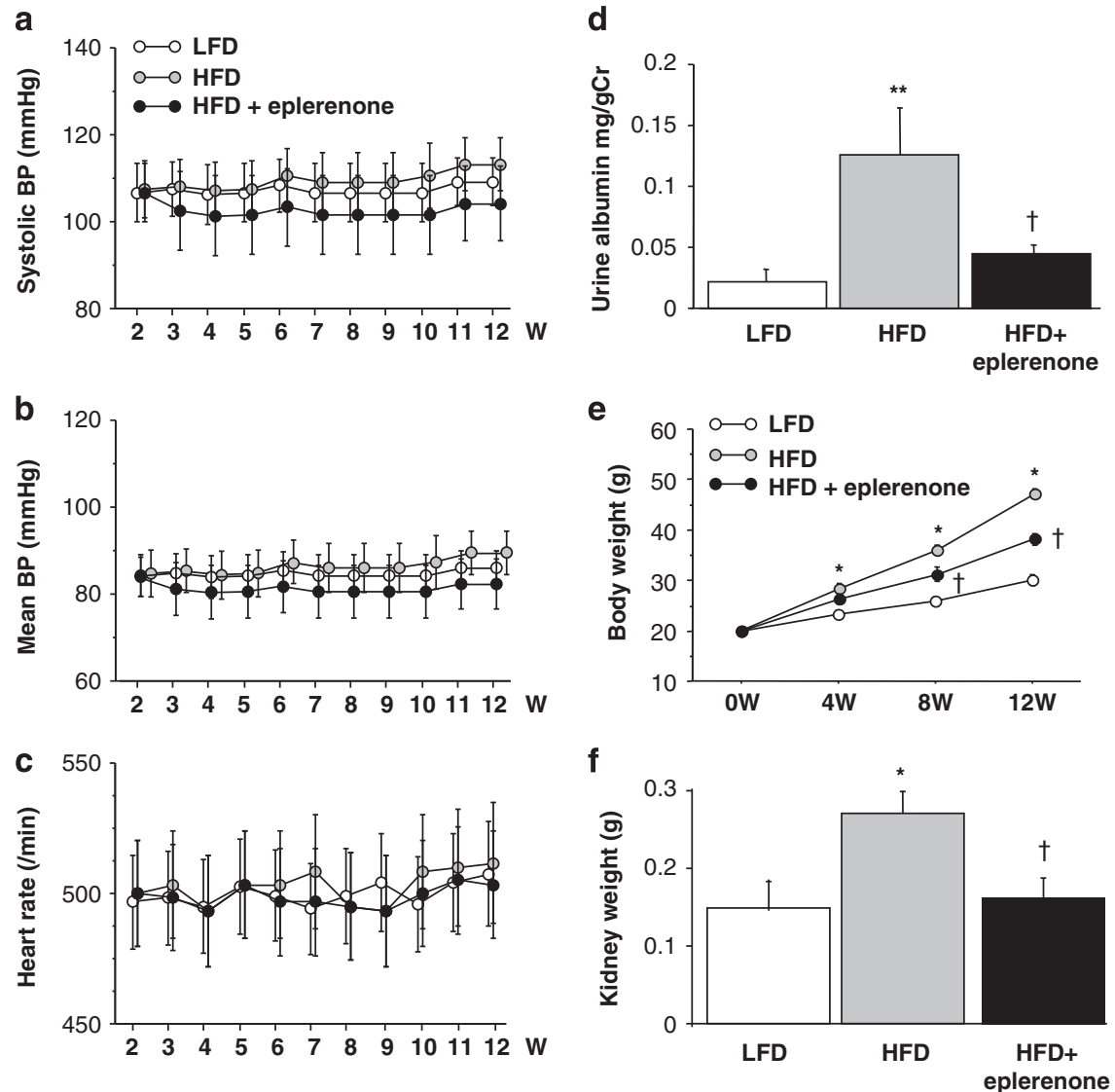

Figure 1. Effects of eplerenone on animal phenotype. (a-c) Systolic BP, mean BP and heart rate were neither unaltered by HFD nor was reduced by eplerenone. (d) Albuminuria was markedly increased in mice on HFD compared with those on LFD. Eplerenone reduced albuminuria. (e, f) Body weights and kidney weights of mice on HFD were markedly greater than those of mice on LFD. The diet-induced obesity was ameliorated by the treatment with eplerenone. Data were expressed as mean \pm s.e.m. $\mathrm{Cr}$, creatinine. ${ }^{*} P<0.05,{ }^{* *} P<0.01$ vs mice on LFD; ${ }^{\dagger} P<0.05$ vs untreated mice on HFD. 
a

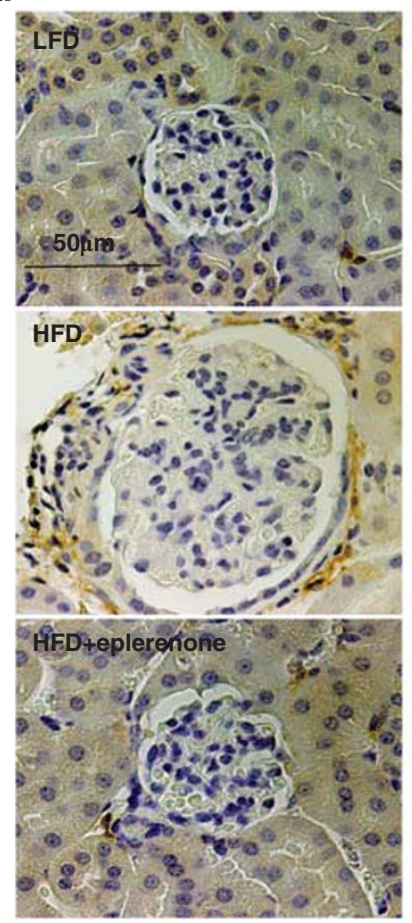

b

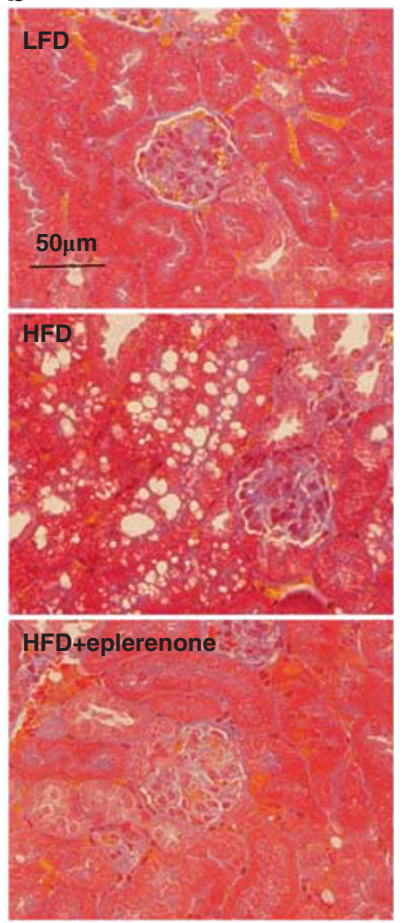

c

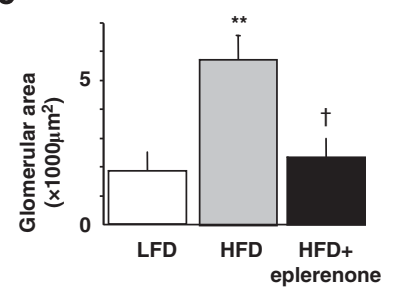

\section{d}

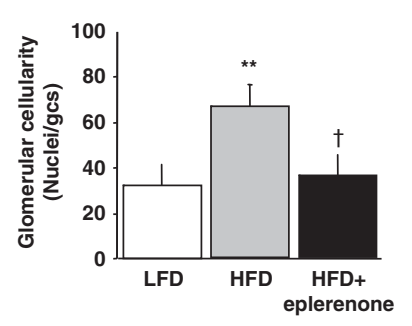

e

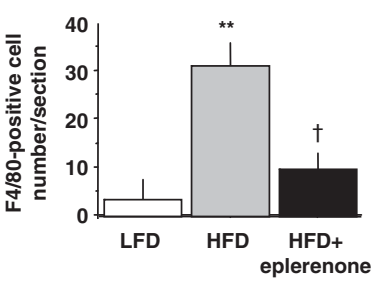

f

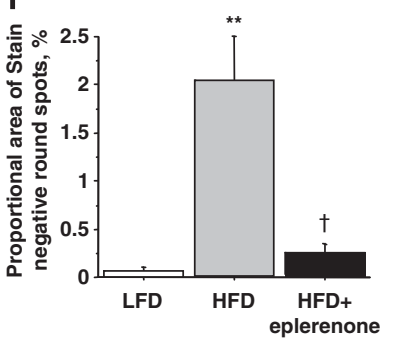

g

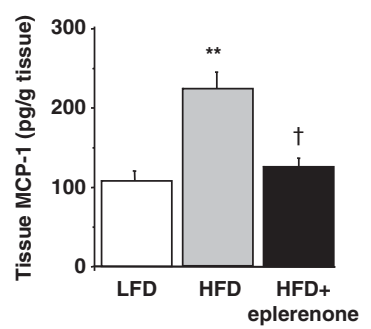

h

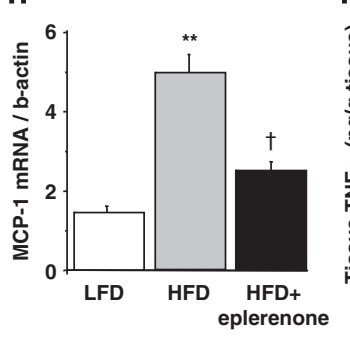

i

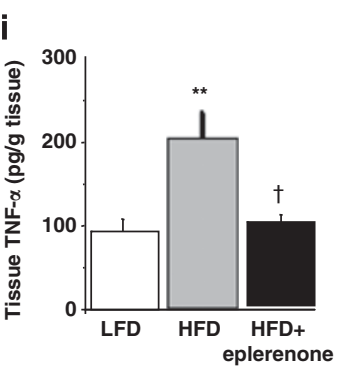

j

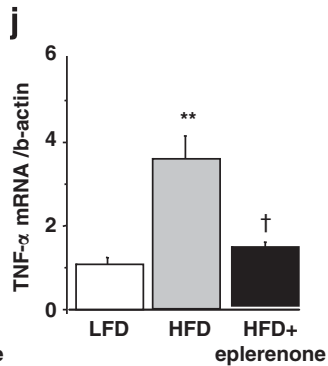

k

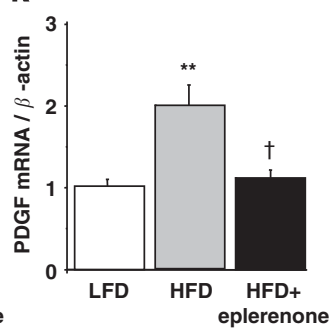

Figure 2. The effects of eplerenone on the HFD-induced renal damages, and renal expression of inflammatory chemokines. (a) Histology of F4/80-stained kidney section from mice on LFD, HFD and HFD with eplerenone. Magnification, $\times 400$. Compared with mice on LFD, untreated mice showed marked glomerular hypercellularity and enlarged glomerular size. Eplerenone-treated mice showed near-normal glomerular histology. (b) Histology of Masson's modified trichrome-stained kidney section from mice on LFD, HFD and HFD with eplerenone. HFD showed no significant fibrotic changes. Alternatively, the stain-negative round spots are increased in tubules in obese mice and were reduced by eplerenone. (c) Glomeruli were markedly enlarged in mice on HFD, which change was reduced by eplerenone. (d) Glomerular cellularity was assessed by the number of nuclei per glomerular cross-section (GCS) in 50 hilar glomeruli per animal. (e) Macrophages were markedly infiltrated in the renal tissue of mice on HFD, which was improved by the treatment with eplerenone. (f) The stain-negative round spots are increased in obese mice and were reduced by eplerenone. HFD-fed mice showed increases in renal expressions of MCP-1 ( $\mathbf{g}, \mathbf{h})$, TNF- $\alpha(\mathbf{i}, \mathbf{j})$ and PDGF-B (k), all of which were attenuated by eplerenone. Data were expressed as the ratio of mRNA levels of MCP-1 (h), TNF- $\alpha$ (j) and PDGF-B (k) to that of $\beta$-actin in arbitrary units (a.u.), relative to controls assigned as a value of 1 . Data were expressed as mean \pm s.e.m. ${ }^{* * P}<0.01$ vs C57BL mice on LFD; ${ }^{\dagger} P<0.05$ vs untreated mice on HFD.

$P<0.01$; Figure 2d). The HFD-induced changes in glomerular size and cellularity were nearly completely abolished by the treatment with eplerenone.

Marked infiltration of macrophages was observed in the renal tissue of mice on HFD (Figure 2e). The treatment with eplerenone pronouncedly abrogated the changes induced by HFD. We examined whether renal fibrotic changes were induced by obesity with Masson trichrome staining. HFD showed no significant fibrotic changes (Figure 2b). Alternatively, the stain-negative round spots were increased in obese mice and were reduced by eplerenone (Figure $2 \mathrm{~b}$ and $\mathrm{f}$ ). HFD-fed mice showed the upregulated renal expressions of MCP-1 (3.5-fold; Figure 2h), TNF- $\alpha$ (3.3-fold; Figure 2j) and PDGF-B (2.0-fold; Figure 2k). Protein levels of MCP-1 and TNF- $\alpha$ were similarly overexpressed in mice on HFD (Figure $2 \mathrm{~g}$ and $\mathrm{i}$ ). All of these changes were abolished by the treatment with eplerenone.
MR and SGK1 expression and aldosterone synthesis enzyme expression in kidneys from HFD-fed mice

Whether the aldosterone signaling pathway was augmented in kidneys from obese mice was examined. In kidneys of HFD-fed mice, MR protein levels in the nuclear fraction were increased (2.3-fold, $P<0.05$; Figure 3a). Similarly, SGK1, a transcriptionally regulated serine-threonine kinase and considered as one of the main effectors of MR-mediated signal transduction, was pronouncedly upregulated (5.5-fold, $P<0.01$; Figure $3 b$ ). The treatment with eplerenone suppressed the MR protein level in the nuclear fraction and downregulated the SGK1 expression.

We further evaluated whether enhanced aldosterone signaling involved aldosterone production per se or the modification of MR function. ${ }^{27}$ Plasma aldosterone levels were unaltered in mice on HFD (Figure 3c). In contrast, renal aldosterone contents were 

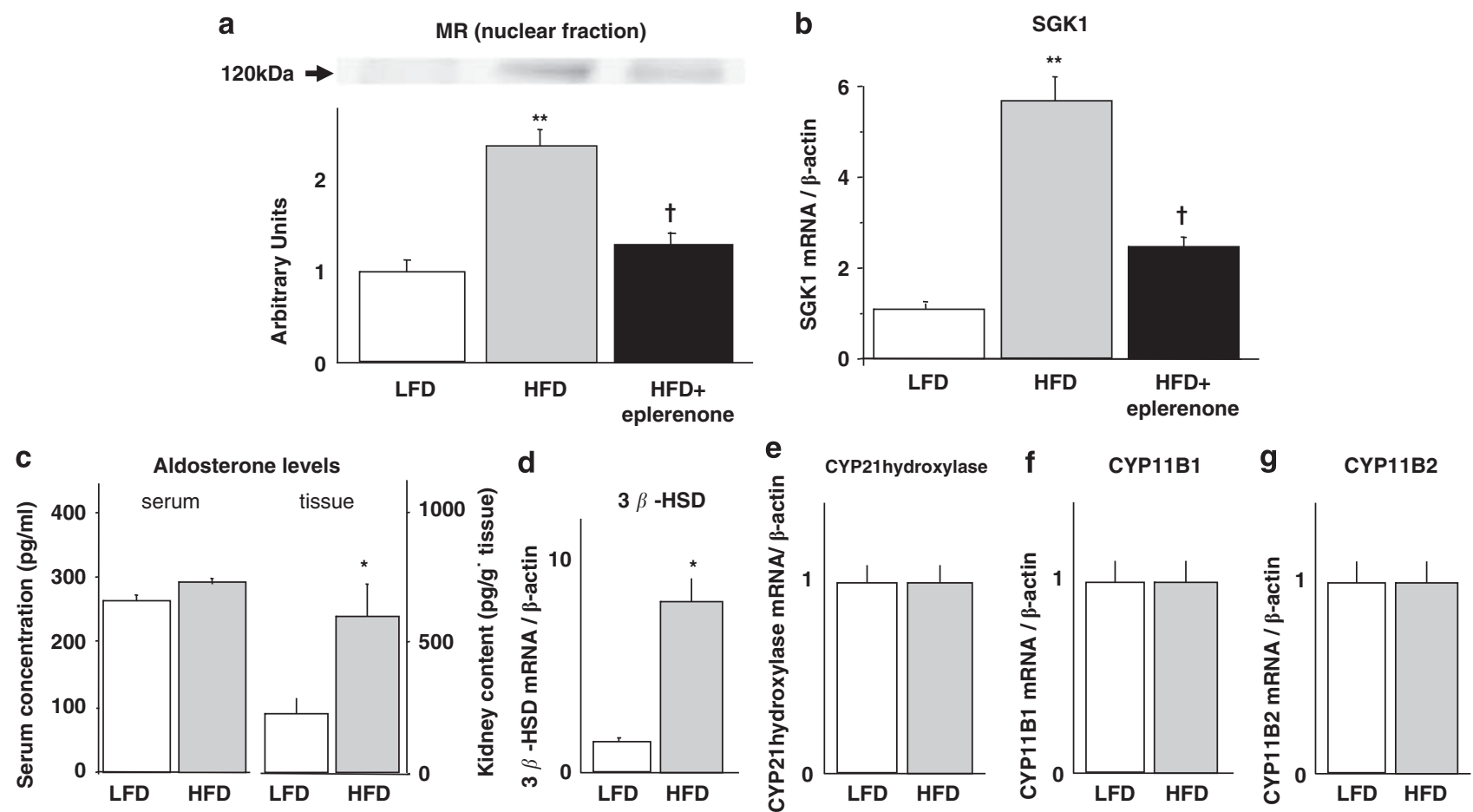

Figure 3. MR and SGK1 expression and aldosterone synthesis enzyme expression in kidneys from HFD-fed mice. (a) The protein in the nuclear fraction representing the MR was increased in HFD, suggesting that MR was enhanced with obesity. (b) HFD-fed mice showed increases in renal expressions of SGK1, which was attenuated by eplerenone. Data were expressed as the ratio of mRNA level of SGK1 to that of $\beta$-actin in arbitrary units (a.u.), relative to controls assigned as a value of 1. (c, left) Serum aldosterone levels did not differ between mice on LFD and those on HFD. (c, right) Tissue aldosterone in the kidneys was markedly increased. (d) HFD-fed mice showed increases in renal

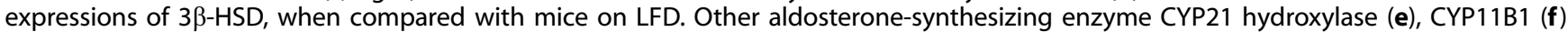
or B2 (g) was unchanged in mice on HFD. Data were expressed as the ratio of mRNA levels of 3 $\beta$-HSD (d), CYP21 hydroxylase (e), CYP11B1 (f) and CYP11B2 (g) to that of $\beta$-actin in arbitrary units (a.u.), relative to controls assigned as a value of 1 . Data were expressed as mean \pm s.e.m. ${ }^{*} P<0.05,{ }^{* *} P<0.01$ vs mice on LFD; ${ }^{\dagger} P<0.05$ vs untreated mice on HFD.

increased by threefold in mice on HFD $(P<0.05)$. The effects of HFD on the enzymes of aldosterone synthesis in renal tissues were evaluated. In HFD-fed mice, mRNA of $3 \beta$-HSD was upregulated (8.0-fold, $P<0.05$; Figure 3d). Other enzymes of aldosterone synthesis, including 21 hydroxylase, CYP11B1 and B2, were unaltered in mice on HFD (Figure $3 e-g$ ).

Rho-kinase activity in the kidney

Whether obesity enhanced the renal Rho/Rho-kinase pathway was examined. HFD significantly increased the level of Thr696phosphorylated MYPT1 in renal tissues (2.0-fold induction, $P<0.05$ vs LFD; Figure 4a). The enhanced Rho-kinase activity was nearly completely abolished by the treatment with eplerenone $(P<0.05$ vs HFD). In contrast, neither p42/44 nor p38 was changed in mice on HFD (Figure $4 \mathrm{~b}$ and $c$ ).

Activation of Rho/Rho-kinase pathway by aldosterone in an MR-dependent manner

Whether the MR activation enhanced Rho kinase was examined in cultured HMCs, using aldosterone as an MR agonist. Increasing concentrations of aldosterone elevated the phosphorylation levels of MYPT1, with a 2.2-fold elevation observed at $1 \mathrm{nmoll}^{-1}(P<0.05$ vs quiescent; Figure $4 \mathrm{~d})$. Stimulation with aldosterone $\left(1 \mathrm{nmoll}^{-1}\right)$ increased the phospho-MYPT1 levels at $90 \mathrm{~min}(1.9 \pm 0.2$-fold induction) and $3 \mathrm{~h}$ (1.4 \pm 0.1 -fold induction; Figure 4e). Pre-incubation with eplerenone $\left(10 \mu \mathrm{molI}^{-1}\right)$ attenuated the aldosterone-induced increase in MYPT-1 phosphorylation in a dose-dependent manner (Figure 4f).
Effects of insulin on MR signaling pathway

SGK1 was upregulated with high concentration of insulin, but not with low concentration of insulin (2.5-fold, $P<0.05$; Figure $4 \mathrm{~g})$.

Effects of fasudil on systemic blood pressure, renal function and metabolic parameters

Systolic BP, mean BP and heart rate were unaltered by fasudil $(P>0.5$; Figure $5 \mathrm{a}-\mathrm{c})$. Serum creatinine levels in obese mice did not differ (LFD, $0.13 \pm 0.02 \mathrm{mg} \mathrm{dl}^{-1}$; HFD, $0.17 \pm 0.05 \mathrm{mg} \mathrm{dl}^{-1}$; HFD with fasudil, $0.13 \pm 0.03 \mathrm{mg} \mathrm{dl}^{-1} ; P>0.1$ ). Albuminuria was markedly increased in mice on HFD, which was reduced by the treatment with fasudil $(P<0.01$; Figure $5 \mathrm{~d}$ ). HFD-induced obesity and enlarged kidneys were ameliorated by the treatment with fasudil ( $P<0.05$; Figure $5 e$ and $f$ ). Fasudil did not affect the amount of food intake (food intake, LFD, $2.0 \pm 0.1 \mathrm{~g}$ per day; HFD, $2.0 \pm 0.1 \mathrm{~g}$ per day, HFD with fasudil, $2.1 \pm 0.1 \mathrm{~g}$ per day).

Effects of fasudil on renal morphological changes and renal expression of inflammatory chemokines

Marked infiltration of macrophages was observed in mice on HFD (Figure $6 a$ and f). The HFD-induced changes in glomerular size and cellularity were nearly completely abolished by the treatment with fasudil (Figure $6 b, d$ and e). The stain-negative round spots were increased in obese mice and were reduced by fasudil (Figure $6 \mathrm{c}$ and $\mathrm{g}$ ).

Furthermore, the upregulated renal expressions, mRNAs (Figure $6 i, k$ and $\mathrm{l}$ ) and protein levels (Figure $6 \mathrm{~h}$ and $\mathrm{j}$ ) of MCP-1, TNF- $\alpha$ and PDGF-B in HFD-fed mice were abolished by the treatment with fasudil. 
a p-MYPT total-MYPT

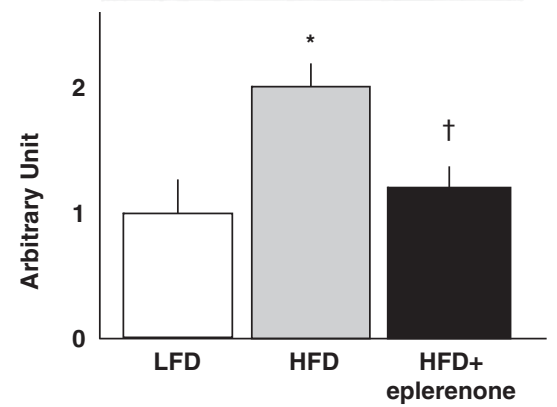

b

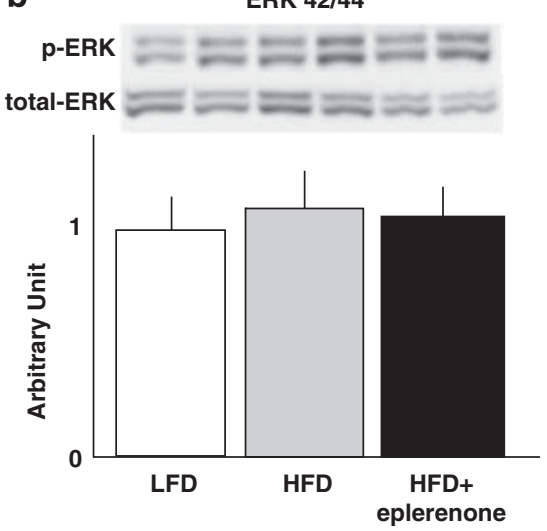

c d
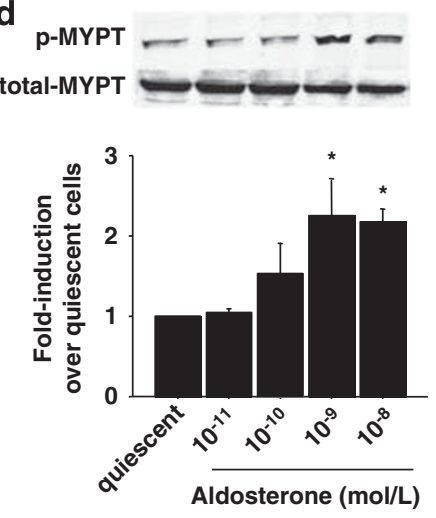

e

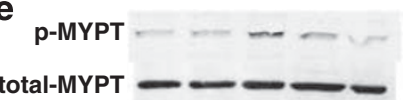

f
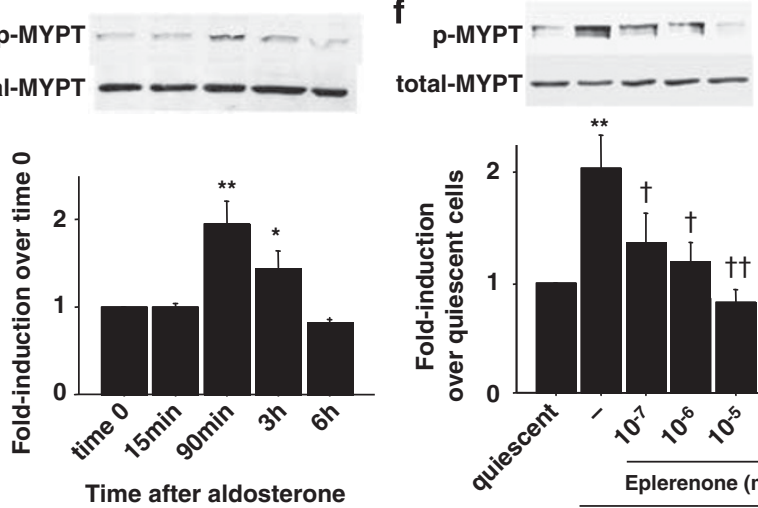
stimulation
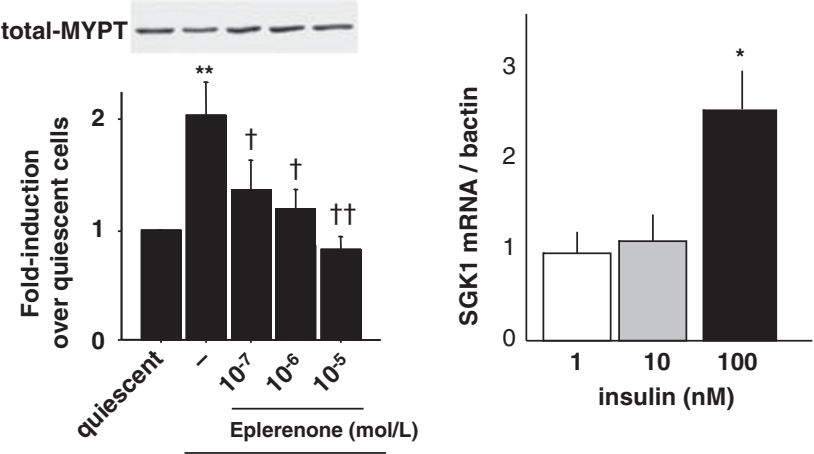

Aldosterone $\left(10^{-9} \mathrm{~mol} / \mathrm{L}\right)$

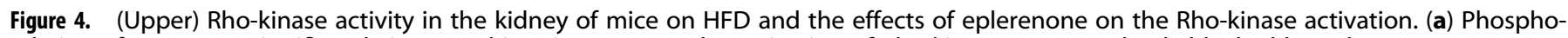
rylation of MYPT was significantly increased in mice on HFD. The activation of Rho kinase was completely blocked by eplerenone treatment. (b, c) p42/44 or p38 in the kidney was unchanged in mice on HFD. Data were expressed as mean \pm s.e.m. ${ }^{*} P<0.05$ vs mice on LFD; ${ }^{\dagger} P<0.05$ vs untreated mice on HFD. (Lower) Effects of aldosterone on Rho/Rho-kinase activity and effects of insulin on MR signaling pathway in primary mesangial cells. The stimulation with aldosterone increased Rho-kinase activity in a dose- $(\mathbf{d}, n=4)$ and a time-dependent manner $(\mathbf{e}, n=4)$. (d) Mesangial cells were incubated with various concentration of aldosterone for $1 \mathrm{~h}$ and the activation of Rho kinase was assayed by immunoblotting. Densitometric analysis of immunoblots is shown as values normalized by the expression levels of total MYPT1. ${ }^{*} P<0.05$ vs quiescent cells. (e) Stimulation with aldosterone $\left(1 \mathrm{nmol} \mathrm{I}^{-1}\right)$ significantly increased the level of phospho-MYPT1 at $90 \mathrm{~min}$ and $3 \mathrm{~h}$. ${ }^{*} P<0.01,{ }^{*} P<0.05$ vs time 0 . (f) Pre-incubation with eplerenone $\left(10 \mu \mathrm{mol} \mathrm{I}^{-1}\right)$ attenuated the aldosterone-induced increase in MYPT-1 phosphorylation in a dose-dependent manner. ${ }^{* *} P<0.01$ vs quiescent; ${ }^{\dagger \dagger} P<0.01,{ }^{\dagger} P<0.05$ vs aldosterone stimulation without pre-treatment. (g) mRNA levels of SGK1 with high insulin treatment. ${ }^{*} P<0.05$ vs $1 \mathrm{nM}, 10 \mathrm{nM}$ of insulin. Results are presented as mean \pm s.e.m.

\section{DISCUSSION}

Obesity and metabolic syndrome are important risk factors not only for cardiovascular complications, but also for the development of proteinuria and CKD. Multiple factors are assumed to contribute to the development of CKD in obesity, including systemic hypertension and dyslipidemia. In this study, we have demonstrated that HFD-induced obesity causes marked renal pathological changes, including glomerular hypercellularity, infiltration of macrophages and stain-negative round spots, which may represent increases in lipid droplets in kidneys from obesity (Figures 2 and 6). Furthermore, these alterations were prevented by the blockade of MR with eplerenone without alterations in systolic and mean BP. In the previous dog study, eplerenone actually lowered BP in obese animals. ${ }^{31}$ In contrast to the dog studies, blood pressure tended to be reduced with eplerenone, but did not attain statistical significance in this study. Because systolic and mean BP were not changed by HFD, the effect of eplerenone might be small. It can be concluded that BP-independent effects of eplerenone are responsible for the reduction in renal injuries. Concomitantly, both nuclear MR protein levels and SGK1 expression in the kidney were elevated in HFD-fed mice, and these actions were abrogated by eplerenone (Figure 3). These observations suggest that the aldosterone/MR pathway constitutes a determinant of the development of CKD in obesity-related nephropathy. Alternatively, the intervention in the aldosterone/MR pathway would provide a clue to the novel therapeutic strategy in obesity-associated nephropathy.

Aldosterone is a potent mineralocorticoid that promotes renal sodium retention and induces hypertension. Several lines of studies have shown that increased serum aldosterone levels are linked to the development of obesity-associated hypertension. ${ }^{32}$ Furthermore, accumulating evidence suggests that the excess aldosterone/MR activity provokes proteinuria and podocyte injury. ${ }^{33}$ In rats with remnant kidney models, aldosterone administration increases proteinuria during the blockade of angiotensin II action with an angiotensin receptor blocker. ${ }^{33}$ Increases in multiple factors, including mitogen-activated protein kinase, ${ }^{15}$ plasminogen activator inhibitor-1, ${ }^{34,35}$ transforming growth factor- $\beta 1^{20}{ }^{20} \mathrm{MCP}-1^{\text {(refs }}{ }^{4,20)}$ and reactive oxygen species, ${ }^{15,36}$ have also been observed in renal tissues of aldosterone-infused animal models. Furthermore, SGK1 is considered as one of the main effectors of aldosterone. ${ }^{37}$ Conversely, the blockade of MR with eplerenone substantially suppresses these parameters, and 

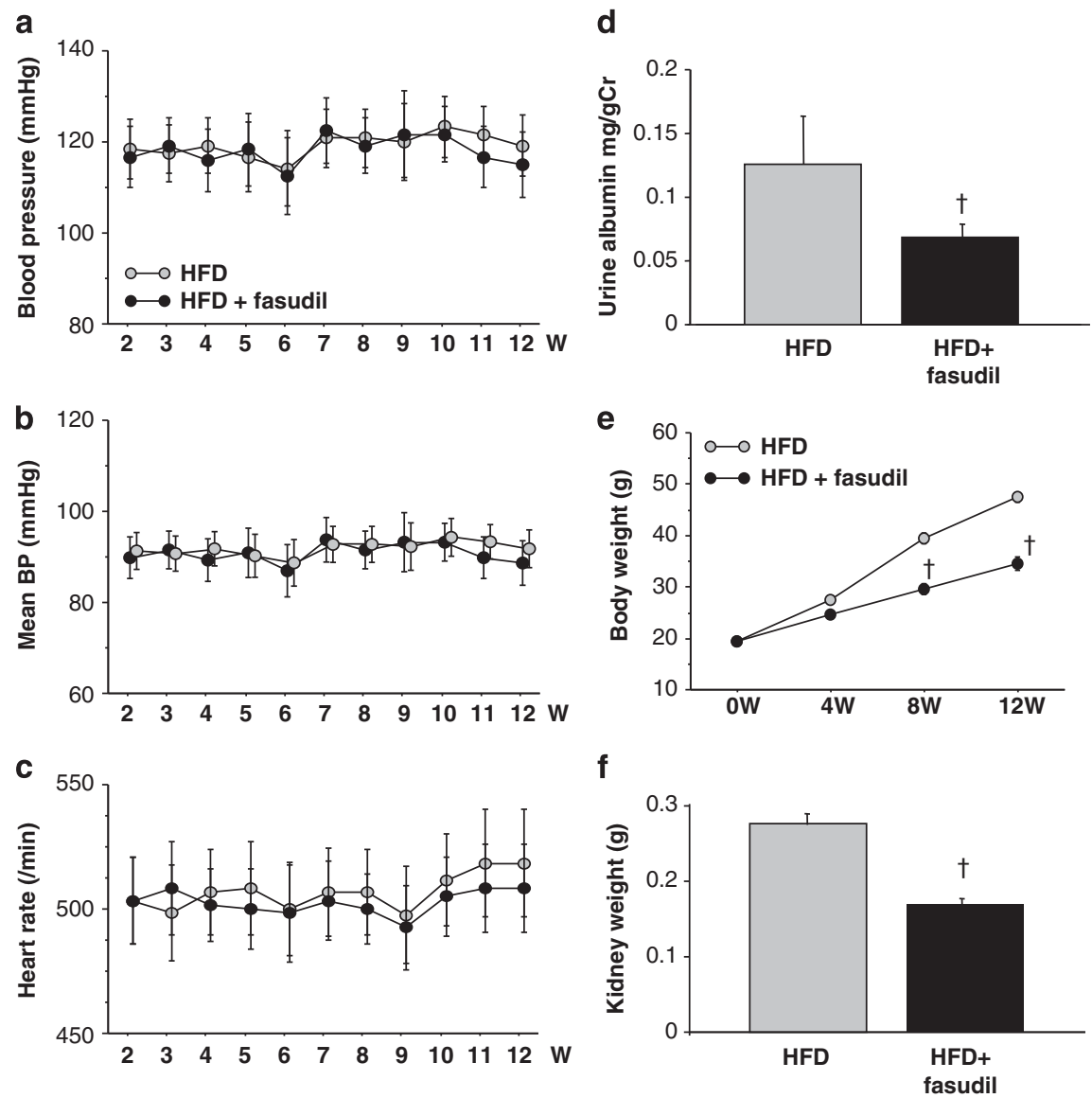

Figure 5. Effects of fasudil on animal phenotype. (a-c) Systolic BP, mean BP and heart rate were unaltered by fasudil. (d) Increased albuminuria in mice on HFD was reduced by fasudil. $(\mathbf{e}, \mathbf{f})$ The diet-induced obesity and enlarged kidneys were ameliorated by the treatment with fasudil. Data were expressed as mean \pm s.e.m. $\mathrm{Cr}$, creatinine. ${ }^{\dagger} P<0.05$ vs untreated mice on HFD.

alleviates the renal injury induced by aldosterone. ${ }^{38,39}$ In this study, we have demonstrated that the blockade of MR with eplerenone ameliorates the obesity-induced renal injury and abrogates the upregulated expression of MCP-1, TNF- $\alpha$ and PDGF-B (Figure 2), as well as SGK1 (Figure 3) in the kidney. These results suggest that obesity-associated renal injury involves the aldosterone/MR-mediated signaling pathway and renal inflammatory process. Although BP and serum aldosterone levels are not changed in this study, the renal arterioles tone may be changed by the reduced afferent arteriolar tone ${ }^{40}$ and the elevated renal tissue aldosterone. ${ }^{41}$ The observed findings (that is, enlarged glomeruli and glomerular hypercellularity) may be induced not by only the overexpression of inflammatory cytokines, but by hyperfiltration of the glomeruli.

Of note, our current study shows the elevation in renal tissue aldosterone contents and the activation of the MR-mediated signaling pathway in obese mice, despite unaltered serum aldosterone levels (Figure 3). Several lines of studies demonstrate that the MR signaling pathway is activated by a variety of factors, including insulin, ${ }^{42}$ renal sympathetic nerve activation ${ }^{43}$ and Rac1. ${ }^{28}$ Aldosterone biosynthesis is mediated by several enzymatic pathways, including 33-HSD, CYP11B2, CYP11A1 and 21-hydroxylase in the adrenal cortex. $A$ recent study has reported that mesangial cells express the mRNA of $3 \beta-H S D, C Y P 11 B 2$ and 21-hydroxylase. ${ }^{44}$ Mesangial cells are an aldosterone-producing tissue, in which LDL plays a major regulatory role in the expression of $3 \beta-\mathrm{HSD}$ and aldosterone production. ${ }^{44}$ In this study, elevated renal tissue aldosterone contents but not serum aldosterone are supposed to account, at least in part, for the activation of the MR pathway in obesity. Of note, in in vitro study, high concentration of insulin induced the overexpression of SGK1 (Figure 4). These results show the link between metabolic disorders and MR signaling pathway in obesity.

Our study raises the possibility that tissue aldosterone is locally produced through the upregulation of $3 \beta-H S D$ in obesity and contribute to effects in the renal glomerulus independently of the systemic renin-angiotensin-aldosterone system. In this regard, the transcription of these genes is regulated through the activation of signaling cascades that could be affected by adipocytokines. ${ }^{45}$ Whether tissue aldosterone could be produced under the condition that aldosterone synthases other than $3 \beta-H S D$ were not changed is not clear. Alternative explanations include increased aldosterone tissue uptake or decreased degradation within tissues. The precise mechanisms for the activation of the MR pathway and the enhanced renal aldosterone production in kidneys from obesity warrant further investigations.

This study has demonstrated the crucial role of Rho/Rho-kinase pathway in the development of nephropathy of non-genetic and HFD-induced obesity in C57BL/6J mice, a mouse model of metabolic syndrome. Evidence has been accumulated that Rho kinase is activated by several stimuli ${ }^{46}$ and is involved in the pathogenesis or aggravation of renal damage in several renal injury and hypertensive models, including subtotally nephrectomized SHR, ${ }^{15}$ Dahl salt-sensitive rats ${ }^{47}$ and aldosterone-infused rats. $^{20}$ In this study, we have demonstrated that HFD-induced obesity causes enhanced Rho-kinase activity in the kidney tissue (Figure 4). We also showed the renoprotective effects of the Rhokinase inhibition (Figures 5 and 6). Furthermore, the activation of 
a

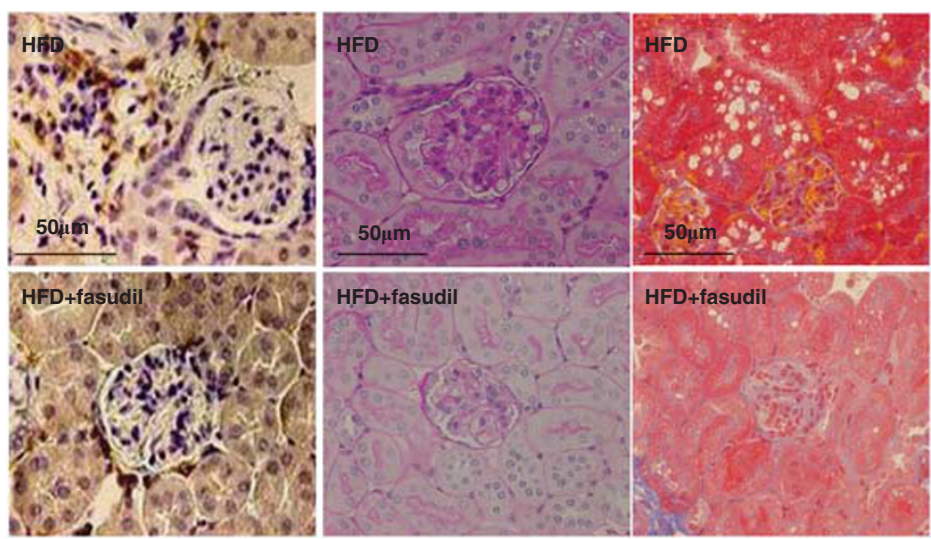

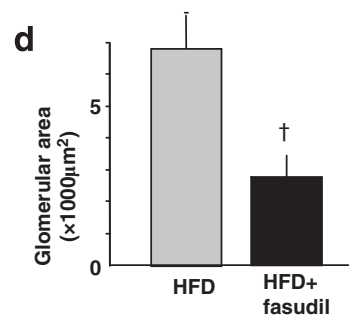
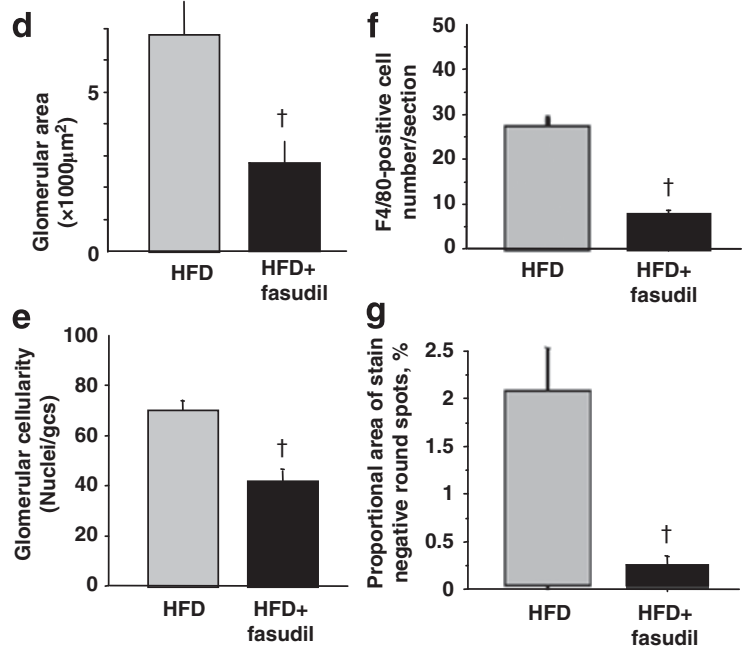
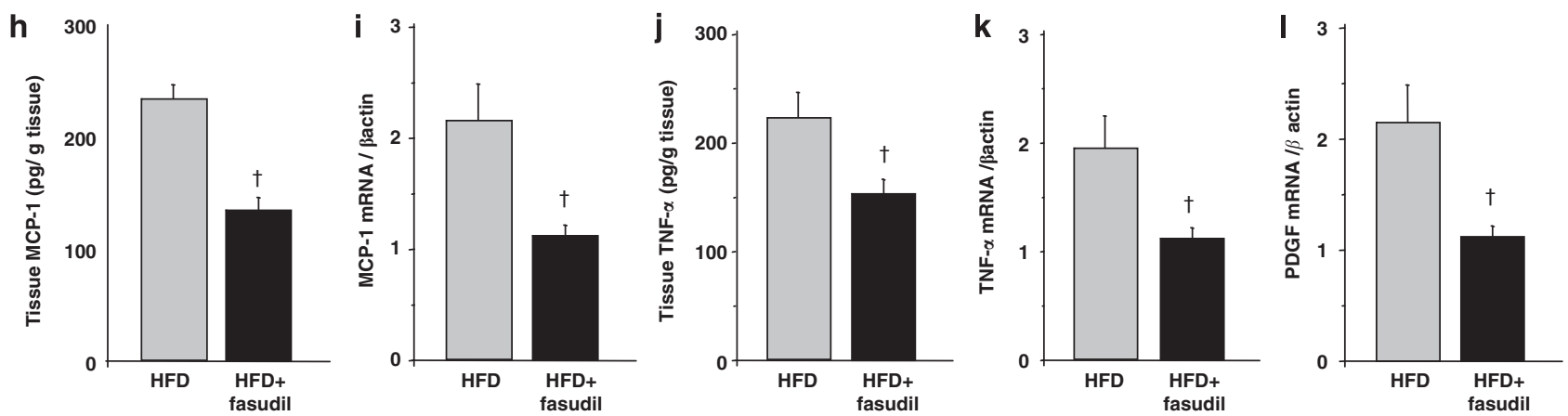

Figure 6. Effects of fasudil on renal morphological changes and renal expression of inflammatory chemokines. (a) Histology of F4/80-stained kidney section from mice on HFD and HFD with fasudil. (b) Periodic acid-Schiff's-stained kidney section. (c) Masson's modified trichromestained kidney section. (d, e) The HFD-induced changes in glomerular size and cellularity were nearly completely abolished by the treatment with fasudil. (f) Macrophages were markedly infiltrated in the renal tissue of mice on HFD, which was improved by the treatment with fasudil. (g) The stain-negative round spots are increased in obese mice and were reduced by fasudil. HFD-fed mice showed increases in renal expressions of MCP-1 (h, i), TNF- $\alpha(\mathbf{j}, \mathbf{k})$ and PDGF-B (I), all of which were attenuated by fasudil. Data were expressed as the ratio of mRNA levels of MCP-1 (i), TNF- $\alpha(\mathbf{k})$ and PDGF-B (I) to that of $\beta$-actin in arbitrary units (a.u.), relative to controls assigned as a value of 1 . Data were expressed as mean \pm s.e.m. ${ }^{\dagger} P<0.05$ vs untreated $\mathrm{C} 57 \mathrm{BL} / 6 \mathrm{~J}$ mice with HFD.

Rho kinase is prevented by the treatment with eplerenone. In vitro study shows that MR stimulation activates Rho kinase in HMCs, which is inhibited by pre-treatment with eplerenone (Figure 4). Since Rho-kinase activation was observed with a peak at 90 min after aldosterone stimulation, non-genomic mechanisms appear to be involved in obesity-induced MR stimulation and the subsequent activation of Rho kinase. Of interest, a previous study shows that in rats treated chronically with aldosterone and salt, renal injury is associated with the activation of mitogen-activated protein kinase, including ERK $1 / 2{ }^{26}$ In our study, however, mitogen-activated protein kinase, ERK1/2 or p38, is not activated in obese mice (Figure 4). Thus, our findings suggest that the enhanced aldosterone/MR signaling pathway plays a key role in renal injury in obesity through the activation of Rho kinase.

Although this study demonstrates activation of MR and Rho kinase in kidneys from obese mice, the subsequent mechanisms for mesangial cell proliferation and macrophage infiltration remain undetermined. Rho kinase is reported to be linked to multiple factors that facilitate inflammation and tissue fibrosis. ${ }^{48}$ Furthermore, our study shows that a Rho-kinase inhibitor (fasudil) abolishes the HFD-induced overexpression of MCP-1, TNF- $\alpha$ and PDGF-B (Figure 6). In this study, we have found that the overexpression of MCP-1, TNF- $\alpha$ and PDGF-B in the renal tissue of obese mice is abrogated by the blockade of the aldosterone/MR pathway (Figure 2). As eplerenone suppresses the upregulated Rho kinase in kidneys of obese mice (Figure $4 a$ ), these cytokines are anticipated to contribute importantly to the development of obesity-induced nephropathy as factors linking between aldosterone/Rho/Rho-kinase pathway and renal injury. The inhibition of Rho kinase by eplerenone may thus offer beneficial action on obesity-related nephropathy through the modification of these cytokines. We have demonstrated that HFD-induced obesity showed the round-shape stain-free spots in tubules, which may be a reminiscence of lipid accumulation areas. Of note, the degree of stain-free areas parallels the levels of several inflammatory markers, including MCP-1, TNF- $\alpha$ and macrophage infiltration, consistent with direct inflammatory changes by lipid accumulation in renal cells. In addition to MR/Rho-kinase pathway, this lipid accumulation may directly cause the overexpression of inflammatory cytokines, leading to the infiltration of inflammatory cells and renal injury.

Finally, the treatment with eplerenone partly prevented all the metabolic changes, including weight gain and hyperinsulinemia, in this study. Thus, it is difficult to discern which effects are due to normalization of obesity and which are due to direct action on the kidney. As we have shown in this study, direct action by the inhibition of MR/Rho/Rho-kinase pathway on the kidney accounts at least for the amelioration of the pathological changes and proteinuria in obesity-induced renal injuries. Moreover, the normalization of obesity itself could be due to the inhibition of MR/Rho/Rho-kinase pathway. This study has unveiled a novel observation showing a possible role of aldosterone in the 
aggravation of obesity. Thus, we demonstrate that HFD-fed obese mice manifest a smaller body weight gain when treated with eplerenone (Figure 1e). In this regard, we previously reported that the inhibition of Rho kinase with fasudil alleviated the increase in body weight in Zucker obese rats, a genetic model of obese animals. ${ }^{13}$ Of note, we have recently demonstrated that in cultured adipocytes, lipid accumulation after the differentiation elicits Rho-kinase activation. Furthermore, mechanical stretch of adipocytes elicits enhancement in Rho-kinase activity. ${ }^{49}$ It is surmised therefore that hypertrophic process during lipid accumulation in adipocytes involves Rho-kinase activation through mechanical stretch as well as MR signaling pathway stimulation, and subsequently induces obesity. The intervention of Rho/Rho kinase and the MR pathway may constitute a novel strategy disrupting vicious circles aggravating obesity.

\section{CONFLICT OF INTEREST}

The authors declare no conflict of interest.

\section{ACKNOWLEDGEMENTS}

We are grateful to Pfizer Inc. for providing eplerenone. The part of this work was presented in an oral form at the American Heart Association-Scientific Sessions, Orlando, 2009. We thank Dr Konishi for advising image analysis.

\section{REFERENCES}

1 Bagby SP. Obesity-initiated metabolic syndrome and the kidney: a recipe for chronic kidney disease? J Am Soc Nephrol 2004; 15: 2775-2791.

2 Henegar JR, Bigler SA, Henegar LK, Tyagi SC, Hall JE. Functional and structural changes in the kidney in the early stages of obesity. J Am Soc Nephrol 2001; 12 : $1211-1217$.

3 Fukata Y, Amano M, Kaibuchi K. Rho-Rho-kinase pathway in smooth muscle contraction and cytoskeletal reorganization of non-muscle cells. Trends Pharmacol Sci 2001; 22: 32 - 39.

4 Kanda T, Wakino S, Hayashi K, Homma K, Ozawa Y, Saruta T. Effect of fasudil on Rho-kinase and nephropathy in subtotally nephrectomized spontaneously hypertensive rats. Kidney Int 2003; 64: 2009-2019.

5 Wehrwein EA, Northcott CA, Loberg RD, Watts SW. Rho/Rho kinase and phosphoinositide 3-kinase are parallel pathways in the development of spontaneous arterial tone in deoxycorticosterone acetate-salt hypertension. J Pharmacol Exp Ther 2004; 309: 1011 - 1019.

6 Nobes C, Hall A. Regulation and function of the Rho subfamily of small GTPases. Curr Opin Genet Dev 1994; 4: 77-81.

7 Narumiya S. The small GTPase Rho: cellular functions and signal transduction. J Biochem 1996; 120: $215-228$.

8 Nakamura A, Hayashi K, Ozawa Y, Fujiwara K, Okubo K, Kanda T et al. Vessel- and vasoconstrictor-dependent role Rho/Rho-kinase in renal microvascular tone. J Vasc Res 2003; 40: 244-251.

9 Cavarape A, Endlich N, Assaloni R, Bartoli E, Steinhausen M, Parekh N et al. Rhokinase inhibition blunts renal vasoconstriction induced by distinct signaling pathways in vivo. J Am Soc Nephrol 2003; 13: 37-45.

10 Ishikawa Y, Nishikimi T, Akimoto K, Ishimura K, Ono H, Matsuoka H. Long-term administration of rho-kinase inhibitor ameliorates renal damage in malignant hypertensive rats. Hypertension 2006; 47: 1075 - 1083.

11 Sugano N, Wakino S, Kanda T, Tatematsu S, Homma K, Yoshioka K et al. T-type calcium channel blockade as a therapeutic strategy against renal injury in rats with subtotal nephrectomy. Kidney Int 2008; 73: 826-834.

12 Begum N, Sandu OA, Ito M, Lohmann SM, Smolenski A. Active Rho kinase (ROKalpha) associates with insulin receptor substrate- 1 and inhibits insulin signaling in vascular smooth muscle cells. J Biol Chem 2002; 277: 6214-6222.

13 Kanda T, Wakino S, Homma K, Yoshioka K, Tatematsu S, Hasegawa K et al. Rhokinase as a molecular target for insulin resistance and hypertension. FASEB J 2006; 20: $169-171$.

14 Blasi ER, Rocha R, Rudolph AE, Blomme EA, Polly ML, McMahon EG. Aldosterone/ salt induces renal inflammation and fibrosis in hypertensive rats. Kidney Int 2003 63: $1791-1800$.

15 Nishiyama A, Yao L, Nagai Y, Miyata K, Yoshizumi M, Kagami S et al. Possible contributions of reactive oxygen species and mitogen-activated protein kinase to renal injury in aldosterone/salt-induced hypertensive rats. Hypertension 2004; 43 $841-848$.
16 Chrysostomou A, Becker G. Spironolactone in addition to ACE inhibition to reduce proteinuria in patients with chronic renal disease. N Engl J Med 2001; 345: 925 - 926.

17 Sato A, Hayashi K, Naruse M, Saruta T. Effectiveness of aldosterone blockade in patients with diabetic nephropathy. Hypertension 2003; 41: 64-68.

18 Rachmani R, Slavachevsky I, Amit M, Levi Z, Kedar Y, Berla M et al. The effect of spironolactone, cilazapril and their combination on albuminuria in patients with hypertension and diabetic nephropathy is independent of blood pressure reduction: a randomized controlled study. Diabet Med 2004; 21: 471 - 475.

19 Williams GH, Burgess E, Kolloch RE, Ruilope LM, Niegowska J, Kipnes MS et al. Efficacy of eplerenone versus enalapril as monotherapy in systemic hypertension. Am J Cardiol 2004; 93: 990 - 996.

20 Sun GP, Kohno M, Guo P, Nagai Y, Miyata K, Fan YY et al. Involvements of Rhokinase and TGF-beta pathways in aldosterone-induced renal injury. J Am Soc Nephrol 2006; 17: $2193-2201$.

21 Kobayashi N, Hara K, Tojo A, Onozato ML, Honda T, Yoshida K et al. Eplerenone shows renoprotective effect by reducing LOX-1-mediated adhesion molecule, PKCepsilon-MAPK-p90RSK, and Rho-kinase pathway. Hypertension 2005; 45: 538-544.

22 Takahashi H, Ichihara A, Kaneshiro Y, Inomata K, Sakoda M, Takemitsu T et al. Regression of nephropathy developed in diabetes by (Pro)renin receptor blockade. J Am Soc Nephrol 2007; 18: 2054 - 2061.

23 Kelly DJ, Chanty A, Gow RM, Zhang Y, Gilbert RE. Protein kinase Cbeta inhibition attenuates osteopontin expression, macrophage recruitment, and tubulointerstitial injury in advanced experimental diabetic nephropathy. J Am Soc Nephrol 2005; 16: $1654-1660$.

24 Zhou HR, Kim EK, Kim H, Claycombe KJ. Obesity-associated mouse adipose stem cell secretion of monocyte chemotactic protein-1. Am J Physiol Endocrinol Metab 2007; 293: E1153-E1158.

25 Yamashita K, Okuyama M, Nakagawa R, Honma S, Satoh F, Morimoto R et al. Development of sensitive derivatization method for aldosterone in liquid chromatography-electrospray ionization tandem mass spectrometry of corticosteroids. J Chromatogr A 2008; 1200: 114-121.

26 Nagai Y, Miyata K, Sun GP, Rahman M, Kimura S, Miyatake A et al. Aldosterone stimulates collagen gene expression and synthesis via activation of ERK $1 / 2$ in rat renal fibroblasts. Hypertension 2005; 46: 1039-1045.

27 Wakino S, Kintscher U, Liu Z, Kim S, Yin F, Ohba M et al. Peroxisome proliferatoractivated receptor gamma ligands inhibit mitogenic induction of p21(Cip1) by modulating the protein kinase Cdelta pathway in vascular smooth muscle cells. J Biol Chem 2001; 276: 47650-47657.

28 Shibata S, Nagase M, Yoshida S, Kawarazaki W, Kurihara H, Tanaka H et al. Modification of mineralocorticoid receptor function by Rac1 GTPase: implication in proteinuric kidney disease. Nat Med 2008; 14: 1370-1376.

29 Zhou L, Yao X, Chen Y. Dexamethasone pretreatment attenuates lung and kidney injury in cholestatic rats induced by hepatic ischemia/reperfusion. Inflammation 2011; (in press).

30 Tatematsu S, Wakino S, Kanda T, Homma K, Yoshioka K, Hasegawa K et al. Role of nitric oxide-producing and -degrading pathways in coronary endothelial dysfunction in chronic kidney disease. J Am Soc Nephrol 2007; 18: 741 - 749.

31 de Paula RB, da Silva AA, Hall JE. Aldosterone antagonism attenuates obesityinduced hypertension and glomerular hyperfiltration. Hypertension 2004; 43: 41 - 47.

32 Thakur V, Richards R, Reisin E. Obesity, hypertension, and the heart. Am J Med Sci 2001; 321: $242-248$.

33 Greene EL, Kren S, Hostetter TH. Role of aldosterone in the remnant kidney model in the rat. J Clin Invest 1996; 98: $1063-1068$.

34 Chun TY, Chander P, Kim JW, Pratt JH, Stier CT. Aldosterone, but not angiotensin II, increased profibrotic factors in the kidney of adrenalectomized stroke prone spontaneously hypertensive rats. Am J Physiol Endocrinol Metab 2008; 295: E305-E312.

35 Ma J, Weisberg A, Griffin JP, Vaughan DE, Fogo AB, Brown NJ. Plasminogen activator inhibitor-1 deficiency protects against aldosterone-induced glomerular injury. Kidney Int 2006; 69: 1064-1072.

36 Shibata S, Nagase M, Yoshida S, Kawachi H, Fujita T. Podocyte as the target for aldosterone: roles of oxidative stress and Sgk1. Hypertension 2007; 49: 355-364.

$37 \mathrm{Hou}$ J, Speirs HJ, Seckl JR, Brown RW. Sgk1 gene expression in kidney and its regulation by aldosterone: spatio-temporal heterogeneity and quantitative analysis. J Am Soc Nephrol 2002; 13: 1190 - 1198.

38 Quinkler M, Zehnder D, Eardley KS, Lepenies J, Howie AJ, Hughes SV et al. Increased expression of mineralocorticoid effector mechanisms in kidney biopsies of patients with heavy proteinuria. Circulation 2005; 112: $1435-1443$.

39 Vallon V, Huang DY, Grahammer F, Wyatt AW, Osswald H, Wulff P et al. SGK1 as a determinant of kidney function and salt intake in response to mineralocorticoid excess. Am J Physiol Regul Integr Comp Physiol 2005; 289: R395-R401.

40 Hayashi K, Kanda T, Homma K, Tokuyama H, Okubo K, Takamatsu I et al. Altered renal microvascular response in Zucker obese rats. Metabolism 2002; 51: $1553-1561$ 
41 Arima S, Kohagura K, Xu HL, Sugawara A, Abe T, Satoh F et al. Nongenomic vascular action of aldosterone in the glomerular microcirculation. $J \mathrm{Am}$ Soc Nephrol 2003; 14: 2255-2263.

42 Lastra-Lastra G, Sowers JR, Restrepo-Erazo K, Manrique-Acevedo C, LastraGonzález G. Role of aldosterone and angiotensin II in insulin resistance: an update. Clin Endocrinol (Oxf) 2009; 71: 1 -6.

43 Lang F, Bohmer C, Palmada M, Seebohm G, Strutz-Seebohm N, Vallon V. Pathophysiological significance of the serum- and glucocorticoid-inducible kinase isoforms. Physiol Rev 2006; 86: $1151-1178$.

44 Nishikawa T, Suematsu S, Saito J, Soyama A, Ito H, Kino T et al. Human renal mesangial cells produce aldosterone in response to low-density lipoprotein (LDL). J Steroid Biochem Mol Biol 2005; 96: 309-316.

45 Jeon JH, Kim KY, Kim JH, Baek A, Cho H, Lee YH et al. A novel adipokine CTRP1 stimulates aldosterone production. FASEB J 2008; 22: $1502-1511$.
46 Sharpe CC, Hendry BM. Signaling. Focus on Rho in renal disease. J Am Soc Nephrol 2003; 14: $261-264$.

47 Nishikimi T, Akimoto K, Wang X, Mori Y, Tadokoro K, Ishikawa Y et al. Fasudil, a Rho-kinase inhibitor, attenuates glomerulosclerosis in Dahl salt-sensitive rats. J Hypertens 2004; 22: 1787 - 1796.

48 Ozawa Y, Kobori H. Crucial role of Rho-nuclear factor-kappa B axis in angiotensin Il-induced renal injury. Am J Physiol 2007; 293: F100-F109.

49 Hara Y, Wakino S, Tanabe Y, Saito M, Tokuyama H, Washida N et al. Rho and Rhokinase activity in adipocytes contributes to a vicious cycle in obesity that may involve mechanical stretch. Sci Signal 2011; 25: ra3.

(c) This work is licensed under the Creative Commons AttributionMMERIGHS RESERVED NonCommercial-No Derivative Works 3.0 Unported License. To view a copy of this license, visit http://creativecommons.org/licenses/by-nc-nd/3.0/ 